\title{
Student Learning Through Social Media
}

\author{
Dr. Roben Taylor \\ Assistant Professor, Curriculum and Instruction, Jacksonville State University, 700 Pelham \\ Rd N, Jacksonville \\ Dr. Franklin King \\ Vice-President Distance Education, Jacksonville State University \\ Email: fking@jsu.edu \\ Dr. Gordon Nelson \\ Retired professor of education, Jacksonville State University \\ Email: gnelson@jsu.edu
}

Accepted: June 17, 2012 Published: July 24, 2012

Doi:10.5296/jsr.v3i2.2136ＵRL: http://dx.doi.org/10.5296/jsr.v3i2.2136

\begin{abstract}
Recent years have witnessed an increased interest in using social media/social learning with online courses. Many students value the social aspects of their university education and hesitate to take online courses thinking them to be devoid of socialization. On the other hand questions have arisen with regard to privacy and instruction into the social dimension of students. This study examined the following questions: 1) Does social media and social learning promotes educational opportunities for improved student understanding? 2) Do students view social media as an asset to courses - does it enhance understanding and keep student engaged? 3) What do university students see as problems with the use of social media? An online survey was developed consisting of 34 questions relating to the demographics of the sampled 1376 university students and questions relating to the previously mentioned questions. Percentages, t-tests, and correlations were analyzed. Results found subtle nuances and interesting trends (as well as further questions), but overall the results indicated positive attitudes and confirm the value of using social media/social learning in online courses. The findings of the study also suggest implications for teaching improvement with online courses at the university level.
\end{abstract}

Keywords: Social media, Academics, FaceBook, collaboration, higher education

\section{Introduction}

Recent years have witnessed an increased interest in using social media/social learning with courses in higher education. New technologies, most often referred to as Web 2.0 have created a growing phenomenon in public and academic use, changing the way organizations and people create, engage, and share existing or newly produced information through 
multi-way communication. With the use of social media interfacing through computer and mobile devices becoming more prevalent, user interaction from the platform to face to face engagement is being promoted (Teclehaimanot \& Hickman, 2011). The most prominent interfaces are Facebook and Twitter. These spaces that allow interactions and the expression of ideas that are carried out through internet technology and the capabilities which encourage communications are referred to in this article as social media. This free flow of information is enhanced through new communication tools and sites that are referred to as social networking sites.

The phrase "social networking sites" is an umbrella term used for social media and includes but is not limited to Facebook, Twitter, Linkedin, Myspace. Social Media is internet based technologies that allow more free flowing communication among its users. New communication tools enhance this communication through audio and visual capturing string, connecting and retrieving features that include:

- Blogs that make authors publish/post their work and invite comments on it.

- Wikis which have capability to promote and facilitate 'common creation' through joining academic ventures.

- Social bookmarking is used to enable users for collating, tagging, and sharing websites of their interests.

- Media sharing spaces provide spaces and opportunities to the user community of posting and sharing pictures, podcasts and videos.

- Collaborative tools extend documents' sharing and editing capabilities to multiple users.

- Social networking sites have abilities of promoting virtual communities to interact and communicate synchronously or asynchronously (Fogel \& Nehmad, 2009).

Given this insight, social networking is reshaping traditional-aged college students. Today, technology has become a major part of students' everyday lives. In this way, the boundaries between online and "real-world" communities are rapidly deteriorating (Lin, 2008). Post-secondary institutions should consider more opportunities to seek creative ways to use social networking in efforts to reach out to students, and strengthen their ties to the institution. More than ever, educators need to know how to skillfully negotiate these technologies to develop academic college-based networks that can help students succeed.

\section{Social Media in Higher Education}

Vygotsky's theory, known as sociocultural perspective, suggests that cognitive growth is influenced by society and culture and not performed in isolation. Therefore, as Ferdig (2007) suggests, social networking promotes interaction between learners and potentially improves active learning as in the student-centered constructivists' environment. Not surprising then is the overwhelming use of social networking sites in four-year colleges. According to Barnes 
and Lescault (2011), 200\% of 456 four-year accredited U.S. institutions reported using some form of social media, with Facebook (used by 98\%) and Twitter (used by $84 \%$ ). While there may be other environments for online engagement, it makes sense to utilize Facebook as a higher education learning tool because students are already engaging in it.

The popularity of Facebook among college students may have begun as a site for college students to network in 2004, but now more non students are joining. Lipka (2007) reported that adults are the fastest growing group of Facebook users and notes that professors are among these adults. As more and more faculty join Facebook, the more opportunities for student-teacher interactions on Facebook increases (Young, 2009). Students are not always positive about these interactions. To illustrate, Mazer, Murphy, and Simonds (2007), reported that as much as half of the students who participated in their study felt it was inappropriate for professors to even be on Facebook. Another topic worthy of investigation is in regards to teacher Facebook use are the positive and negative effect on student attitudes associated with their teacher. Among the benefits is that students have the opportunity to better know their professors. However, in doing so, professors run the risk of losing their professionalism as students delve into their postings, pictures, and personal profile information.

In light of the aforementioned discussion, this study aims at exploring the practices and problems of academic use of social media/social learning at the higher education level.

\section{Materials and Methods}

\subsection{Sample}

The subjects consisted of 1376 University students from 18 to over 50 years of age, with $32 \%$ males and $68 \%$ females, $79 \%$ who were full-time and $21 \%$ who were part-time students, and $21 \%$ who lived on campus and $79 \%$ who lived off campus.

\subsection{Procedure}

For ease of responding, a short survey questionnaire was prepared consisting of 18 questions, later to be statistically analyzed as 34 questions, as some of the questions had multiple responses. The survey was administered online to 8,486 students through the Jacksonville State University, Office of Instructional Research and Assessment, with four e-mail reminders, using current programs available for university sampling. Students were given almost a month (from January 18 to February 13) to respond to the questionnaire. The return rate was 1,376 (about 16\%).

\subsection{Data Analysis and Results}


Data was converted to Microsoft Excel and then further converted to SPSS where frequencies, correlations, and t-tests were used to analyze the data. Continuous variables (Ordinal and Interval data) were used in frequencies and correlations. Categorical data (nominal data) included the following variables: gender, students living on or off campus, and full or part-time students.

The age of the students indicated a significant mean difference between on and off campus students with younger students tending to live on campus and older students living off campus. There was also a significant mean difference between full and part-time students with full-time students being younger. These data were to be expected and therefore confirmed the reliability of the results.

Students indicated an average of about 23 hours per week spent doing internet activities for school, work, or recreation, with females spending more time on internet activities than males. Other questions related to the hours spent texting, interrogating the University library, and social networking (e.g. Facebook, etc.) indicated (significant t-test differences) that full-time students, females, and those who live on campus tend to spend more time on the internet.

The results indicate that students typically use social networks to keep in touch with their friends and to share photos; however, about $16 \%$ indicated they communicate with their classmates about course related topics. This suggests social interactions take precedence over academic internet interactions. These results are to be expected, but as classes begin to use the internet more in coursework; this percentage should be expected to rise.

Results show that students who indicated that they don't participate in social networks claim that the main reason is that they are just not interested. The second reason is privacy concerns, followed by not having enough time, as well as having security concerns (viruses, etc.). Results also showed that most students who frequently use the internet most often spend their time with videos (YouTube) and photo sites instead of wikis or blogs. It was also found that more than other types of internet interactions, students most enjoy learning how to do competent internet searches. This might be an indication of future motivational factors as professors begin to integrate students into coursework internet usage.

Most students indicated that they prefer a moderate use of social learning in their classes; further t-tests indicate that females, students on campus, and full-time students prefer social learning in their classes more than males, students off campus and part-time students. This is further indication of the higher interest in socialization among females, as well as the suggestions that off campus and part-time students are more concerned with jobs and possible family responsibilities.

Results have indicated that social networking is not used much in classes and most of the computer usage is centered on PowerPoint and searching university library websites. Despite the lack of social networking incorporated into class, students have responded that they feel 
confident in using these methods upon graduation from university.

The majority of students feel that it would benefit the university to have more online courses, with females, part-time students, and students doing off campus students preferring online courses the most. This again is expected and further confirms the reliability of the results. It also underscores the target population for online courses. An interesting question in the survey found that most students would not skip classes if the lectures were available online. This indicates that students prefer the interaction in a classroom, rather than just watching a one dimensional lecture on the internet. It also suggests that online course preparation should include some interactive strategies - a major topic to be addressed in the future as the need for online courses accelerates.

Students generally were more neutral on the question of whether they get more "involved" in courses that use social media, or that it is "improves" their learning, or that it makes the assignments more "meaningful." High correlations (in the $.80 \mathrm{~s}$ ) did indicate, however, a strong relationship between these 3 essential goals for classroom learning (i.e., students becoming more involved, pedagogy that improves learning, and wanting to enhance meaningful learning). Also, females feel that social media makes courses more meaningful than males, again confirming the higher need and interest in socializing in women.

An interesting question indicated that males feel they are more competent in computer expertise than females, despite the finding that females spend more time on the computer than males, due to the highly motivational socialization feature. It's possible that females might be more expert in computer usage than they realize, and that past insecurities might be unwarranted. These insecurities might come from the overuse of computer jargon and terminology used more by males.

\section{Discussion/Implications/Conclusions}

To revisit our initial three major questions, first "Does social media and social learning promote educational opportunities for improved student understanding?" For some students with a need for socialization, it can be highly motivating. A recent phenomenon finds women beginning to outnumber men in education, and as seen in the results of this study, there is reason to believe that the higher need for socialization among women over men will increase the need for social media and social learning, and promote educational opportunities for improved student understanding.

Second, "Do students view social media as an asset to courses - does it enhance understanding and keep students engaged?" Again, females respond more positively to social media and view it as an asset to courses more than do males. There is also another dimension to consider. Psychology has long recognized the extraversion-introversion continuum in human personality and behaviors (Eysenck, 1971). Extroverts prefer more social activity in the classroom, whereas introverts might find social networking unpleasant. So the question of 
the efficacy of social media might best be answered, "yes" for some and "no" for others. Giving choices to students might be the best strategy in the end. Further research should explore the strength of extroversion/introversion attributes in course motivation and satisfaction.

Third, "What do university students see as problems with the use of social media?" As we have seen in this study, there are "different strokes, for different folks" based on gender (females preferring a more social media orientation), off campus and part-time students (who don't have the time or inclination for social networking based on the presumption that they have jobs and family responsibilities), and that social networking is still the "new kid on the block" and, as the results show, it's not being used very much at the present. This suggests a need for training for professors to become more comfortable with social media in their classrooms, and perhaps be in a position to model and effectively use and develop skills in this area.

\section{References}

Barnes, N.G. \& Lescault, A. M. (2011). Social media soars as higher-ed experiments and reevaluates its use of new communications tools. Retrieved online June 10, 2012, from tyyp://www.umassd.edu/media/umassdartmouth/cmr/studiesandresearch/higherEd.pdf

Eysenck, H. J. (1971), Readings in extraversion-introversion. New York, Wiley-Interscience.

Ferdig, R. E. (2007). Editorial: Examining social software in teacher. Journal of Technology \& Teacher Education, 15(1), 5-10.

Fogel, J., \& Nehmad, E. (2009). Internet social network communities: Risk taking, trust and privacy concerns. Computers in Human Behavior, 25(1), 153-160.

Lin, J. (2008). Research shows that internet is rewriting our brains. October 15, 2008, from UCLA Today: http:..www.today.ucla.edu/portal/ut/081015_gary-small-ibrain.aspx .

Lipka, S. (2007). For professors, 'friending' can be fraught. Chronicle of Higher Education, 54(15), A1-A28.

Mazer, J.P., Murphy, R. E., \& Simmonds, C. J. (2007). I'll see you on "Facebbok":The effects of computer-mediated teacher self-disclosure on student motivation, affective learning and classroom climate. Communication Education, 36(1), 1-17.

Teclehaimanot, B., \& Hickman, T. (2011). Student-teacher interaction of Facebook: What students find appropriate. TechTrends, 55(3), 19-30. 
Young, J. R. (2009). How not to lose face on Facebook, for professors. Chronicle of Higher Education, 55(2), A1-A13. 